\title{
Evaluation of the relationship between the cost and properties of glass ionomer cements indicated for atraumatic restorative treatment
}

\begin{abstract}
Ana Flávia Bissoto CALVO Ariane KICUTI

Tamara Kerber TEDESCO Mariana Minatel BRAGA

Daniela Prócida RAGGIO
\end{abstract}

Universidade de São Paulo - USP, School of Dentistry, Department of Orthodontics and Pediatric Dentistry, São Paulo, SP, Brazil.

Declaration of Interests: The authors certify that they have no commercial or associative interest that represents a conflict of interest in connection with the manuscript.

Corresponding Author:

Daniela Prócida Raggio

E-mail:danielar@usp.br

DOI: 10.1590/1807-3107BOR-2016.vol30.0008

Submitted: Dec 22, 2014

Accepted for publication: May 27, 2015

Last revision: Aug 27, 2015

\begin{abstract}
The aim of this study was to evaluate microshear bond strength $(\mu \mathrm{SBS})$, water sorption and solubility of glass ionomer cements (GIC) indicated for atraumatic restorative treatment (ART). Cylindrical specimens $(6 \times 2.4 \mathrm{~mm})$ were used to test the sorption and solubility of each GIC ( $n=5)$. The specimens were weighed before and after immersion in water and desiccation. For the $\mu S B S$ test, 60 primary molars were ground to obtain flat surfaces from both enamel and dentin. The teeth were then assigned to the tested GIC $(n=10)$ groups, namely Fuji IX - FIX, Ketac Molar - KM and Maxxion R - MX. The exposed surfaces were pre-treated with GIC liquid. Polyethylene tubes were placed on the pre-treated surface and filled with one of the GIC. After $24 \mathrm{~h}$, the specimens were submitted to the $\mu$ SBS test. The failure mode was assessed using a stereomicroscope (400x magnification). The powder to liquid ratio and cost of material were also determined $(\mathrm{n}=3)$. The data were analyzed by ANOVA and Tukey's post hoc test. Linear regression was used to determine the relation between cost and the other variables. Overall, MX showed lower $\mu S B S$ values (enamel: $3.93 \pm 0.38$; dentin: $5.04 \pm 0.70$ ) than FIX (enamel: $5.95 \pm 0.85$; dentin: $7.01 \pm 1.06$ ) and KM (enamel: $5.91 \pm 0.78$; dentin: $6.88 \pm 1.35$ ), as well as higher sorption and solubility. The regression analyses showed a significant and positive correlation between cost and $\mu$ SBS in enamel $\left(\mathrm{R}^{2}=0.62 ; \mathrm{p}<0.001\right)$ and dentin $\left(\mathrm{R}^{2}=0.43 ; \mathrm{p}<0.001\right)$; and a negative correlation between cost and water sorption $\left(R^{2}=0.93 ; p<0.001\right)$ and solubility $\left(R^{2}=0.79 ; p<0.001\right)$. In conclusion, the materials indicated for ART exhibit distinct physical and mechanical properties; in addition, low-priced materials may interfere with GIC properties.
\end{abstract}

Keywords: Costs and Cost Analysis; Solubility; Shear Strength.

\section{Introduction}

Atraumatic restorative treatment (ART) is part of the Basic Package of Oral Care (BPOC) recommended by the World Health Organization (WHO), together with other essential components: oral urgent treatment and affordability of fluoride toothpaste. ${ }^{1}$ ART promotes a less traumatic treatment, as it does not require conventional rotary equipment or the use of a rubber dam, and is therefore a patient-friendly approach. ${ }^{2,3,4}$ In this sense, ART could 
be considered a satisfactory method for caries control in the public oral health setting, since its ease of use shortens the length of treatment and, consequently, reduce cost $^{5}$ without compromising effectiveness. ${ }^{6}$

The high-viscosity glass ionomer cement (GIC) is the adhesive material recommended for this technique, as it is biocompatible, has a coefficient of thermal expansion similar to that of the teeth, and releases fluoride. ${ }^{78,9,10}$ Another peculiar characteristic of GIC concerns water uptake and loss after handling. Water sorption and solubility can result in hydrolytic degradation and, consequently, compromise the mechanical properties of GIC. ${ }^{8,9,11,12}$

Amorim et al., ${ }^{6}$ in a systematic review, concluded that high-viscosity (HV) GIC provides long-lasting restorations for primary and permanent teeth. However, the high cost of HVGIC is a drawback, which could restrict the access of the population to its benefits, mainly in the public health setting.

Cost analyses are important in that they provide dental practitioners with crucial information, helping them make decisions about treatment and also about planning, management, and health promotion processes. ${ }^{13}$ That being considered, the purpose of this study was to evaluate microshear bond strength, and water sorption and solubility of GIC indicated for ART to verify if the use of low-priced materials interferes with GIC mechanical properties.

\section{Methodology}

The study protocol was approved by the Research Ethics Committee of the School of Dentistry, Universidade de São Paulo - USP (protocol \#114/11).

The materials used, manufacturers, and compositions are described in Table 1. For the sake of comparison, Fuji IX was used as the control.

\section{Microshear bond strength test ( $\mu \mathrm{SBS})$}

Sixty primary molars were selected, disinfected in a $0.5 \%$ chloramine solution, and stored in distilled water at $4^{\circ} \mathrm{C}$ until use. The root portion of the teeth was removed in the cross-sectional plane at approximately $1 \mathrm{~mm}$ below the cement-enamel junction.

For the enamel bond strength analysis, the crowns of 30 primary molars were sectioned mesiodistally using a low-speed water-cooled diamond saw in a cutting machine (Labcut 1010, Extec Co., Enfield, USA) in order to obtain the enamel sections. The buccal and lingual surfaces were then ground using a 320 grit silicon carbide abrasive paper in a polishing machine (Buehler Ecomet V, Buehler Ltd, Lake Bluff, USA) in order to obtain flat and smooth enamel surfaces. The dentin bond strength of the remaining 30 teeth was determined by grinding the occlusal surface with the same abrasive paper and polishing machine until all the enamel was removed. The superficial dentin surfaces - the first surfaces after total removal of enamel islets - were used for the $\mu$ SBS analysis. Additionally, all teeth were polished with a 600 grit silicon carbide paper for $60 \mathrm{~s}$ to produce a standardized smear layer. ${ }^{14}$

For each substrate (enamel and dentin), the teeth were randomly assigned to three groups $(n=10)$ according to the restorative material used: (1) Fuji IX gold label - control group (FIX - GC Corporation); (2) Ketac Molar Easymix (KM - 3M ESPE), and (3) Maxxion R (MX - FGM) (Table 1).

The surfaces were pre-treated with GIC liquid, which was applied to the flat surface for $10 \mathrm{~s}$. At least three polyethylene tubes per tooth (internal diameter of $0.76 \mathrm{~mm}$ / height of $1.0 \mathrm{~mm}$, Micro-bore ${ }^{\circledR}$ Tygon S-54-HL Medical Tubing, Saint-Gobain Performance Plastics, Akron, USA) were placed on the pre-treated

Table 1. Glass lonomer Cement: material, manufacturer and composition, proportion powder:liquid and cost per portion (US\$).

\begin{tabular}{|c|c|c|c|c|}
\hline Material & Manafature & Composition & Powder:liquid $(\mathrm{g} / \mathrm{g})$ & Cost/portion (US\$) \\
\hline $\begin{array}{l}\text { Fuji IX Gold } \\
\text { Label (F IX) }\end{array}$ & $\begin{array}{l}\text { GQ Corporation } \\
\text { Tokyo, Japan }\end{array}$ & $\begin{array}{l}\text { Powder: fluoro- aluminum silicate glass; polyacrylic acid powder } \\
\text { Liquid: polyacrylic acid; distilled water }\end{array}$ & 3.55 & 2.02 \\
\hline $\begin{array}{l}\text { Ketac }^{T M} \text { Molar } \\
\text { Easy Mix (KM) }\end{array}$ & $\begin{array}{l}\text { 3M/ESPE } \\
\text { Seefeld, } \\
\text { Germany }\end{array}$ & $\begin{array}{l}\text { Powder: calcium aluminum-lanthanum-fluorosilicate glass, } \\
\text { copolymer acid (acrylic and maleic acid), pigments } \\
\text { Liquid: water, acrylic acid-maleic acid copolymer, tartaric acid }\end{array}$ & 2.55 & 1.46 \\
\hline Maxxion $R(M X)$ & $\begin{array}{l}\text { FGM Joinville, } \\
\text { Brazil }\end{array}$ & $\begin{array}{l}\text { Powder: fluoro aluminum silicate glass, potassium fluoride and pigments } \\
\text { Liquid: polyacrilic and tartaric acid; water }\end{array}$ & 1.38 & 0.12 \\
\hline
\end{tabular}


surface, filled with one of the GIC, covered with a matrix strip, and gently pressed with a glass slide. ${ }^{15}$ A thin layer of petroleum jelly was applied to the exposed GIC surface to avoid water uptake and loss. All GIC were mixed according to the manufacturer's instructions. The bonding and restorative procedures were carried out at room temperature by a previously trained operator.

The specimens were then stored in distilled water for $24 \mathrm{~h}$. Thereafter, they were attached to a universal testing machine (Kratos Industrial Equipment, Cotia, Brazil) and a $0.20 \mathrm{~mm}$ thin wire was looped around the projection of the load cell and of the GIC cylinder, maintaining contact with the surface of the tooth as close as possible to the GIC-substrate interface. The microshear bond strength test ( $\mu \mathrm{SBS}$ ) was performed at a crosshead speed of $1.0 \mathrm{~mm} / \mathrm{min}$ until failure. The failure mode was determined under a stereomicroscope using 400x magnification (Discovery V20, Zeiss, Oberkochen, Germany) and classified as adhesive/mixed or cohesive failure (in GIC or substrate). Mixed failures were those that occurred mainly within adhesive interfaces, but also included small areas of GIC or enamel/dentin. Only the specimens that exhibited mixed/adhesive failures were used to calculate average bond strength.

\section{Water sorption and solubility}

Disc-shaped specimens $(n=5)$ measuring $6 \mathrm{~mm}$ in diameter and $2.4 \mathrm{~mm}$ in height were prepared in a stainless steel mold between two glass slides and covered with a matrix strip. The GIC specimens were prepared and the surfaces protected according to the manufacturer's instructions in order to avoid dehydration.

All specimens were stored in a desiccator at $37^{\circ} \mathrm{C} \pm$ $1^{\circ} \mathrm{C}$ with silica gel for $24 \mathrm{~h}$. Afterwards, the specimens were stored in a desiccator at $23^{\circ} \mathrm{C} \pm 1^{\circ} \mathrm{C}$ for $1 \mathrm{~h}$ and were weighed until verification of mass stabilization, considering this measure as the initial mass $\left(\mathrm{M}_{1}\right)$. Thereafter, they were stored separately in $10 \mathrm{~mL}$ of distilled and deionized water at $37^{\circ} \mathrm{C}$ for 7 days. ${ }^{16}$ After that, they were dried with absorbent paper and received an air jet for $15 \mathrm{~s}$; each disc was weighed to obtain the mass after saturation with water $\left(\mathrm{M}_{2}\right)$. Then, all the specimens were placed in the desiccator again at $37^{\circ} \mathrm{C}$ and reweighed until a constant weight was achieved $\left(\mathrm{M}_{3}\right)$. Weighing was performed using an analytical scale with an accuracy of $0.0001 \mathrm{~g}$. The volume $(\mathrm{V})$ of each specimen was calculated by the following equation: $V=p^{2} h$, where $p=3.1415 ; r$ is the radius and $h$ is the thickness of the specimens. Diameter and thickness were measured using a digital caliper with an accuracy of up to $0.01 \mathrm{~mm}$. Water sorption (WS) and solubility (SL), expressed in $\mu \mathrm{g} / \mathrm{mm}^{3}$, were calculated for each specimen using the following equations: WS $=\left(\mathrm{M}_{2}-\mathrm{M}_{1}\right) / \mathrm{V}$ and $\mathrm{SL}=\left(\mathrm{M}_{1}-\mathrm{M}_{3}\right) / \mathrm{V}$.

\section{Determination of the powder to liquid ratio and cost of material}

The powder to liquid ratio of the materials was estimated using an analytical scale with an accuracy of $0.0001 \mathrm{~g} \cdot{ }^{17}$ The average weight was then calculated, as well as the number of portions from each bottle. A previously trained operator performed both analyses in triplicate. The cost of the material was determined by the average prices obtained from three different dental supplies stores. After determining the number of portions available in each kit, the cost was estimated per portion.

\section{Statistical analysis}

The MedCalc statistical software v. 12.5.0.0 (Mariakerke, B-8400, Ostend, Belgium) was used for all data analyses. The normality of the data and homoscedasticity of variance were assumed after the Kolmogorov-Smirnov and Levene's tests. The $\mu$ SBS, sorption and solubility means were submitted to one-way analysis of variance (ANOVA) and Tukey's post-hoc test. For the $\mu \mathrm{SBS}$ analysis, the $\mu \mathrm{SBS}$ values of all cylindrical specimens obtained from the same tooth were averaged for statistical purposes.

The failure mode was evaluated qualitatively. Linear regression was used to investigate the relationships between cost per portion of material and properties of the materials. The level of significance was set at $5 \%$.

\section{Results}

The means and standard deviations of the $\mu$ SBS test are summarized in Table 2 . The statistical analyses 
yielded significant differences between the GIC in primary enamel and dentin. MX showed lower $\mu$ SBS values than FIX and KM ( $\mathrm{p}<0.05)$ for both substrates. No statistical difference was observed between the FIX and KM groups ( $p>0.05)$. The failure mode and the percentage of pre-testing failures observed are shown in Table 3. There was a predominance of adhesive/ mixed failures, whereas no cohesive failures in dentin and enamel were verified in any of the experimental groups. The largest number of premature failures was observed in the MX bonded to dentin.

The mean values and standard deviations of water sorption and solubility are displayed in Figures 1 and 2, respectively. ANOVA showed that the water sorption of GIC is significantly different among the materials tested $(p<0.001)$, whereas MX presented the highest value among all the other materials $(p<0.001)$. Similarly, MX revealed significantly higher solubility than FIX and KM ( $p>0.05)$.

The powder to liquid ratio and cost per portion are presented in Table 1. The regression analyses showed a positive and significant correlation between cost and $\mu$ SBS in enamel $\left(R^{2}=0.62 ; p<0.001-\right.$ Figure 3$)$ and between cost and $\mu S B S$ in dentin $\left(R^{2}=0.43\right.$; $p<0.001$ - Figure 4). On the other hand, a significant and negative correlation was verified between cost and water sorption $\left(R^{2}=0.93 ; p<0.001-\right.$ Figure 5) and cost and solubility $\left(R^{2}=0.79 ; p<0.001\right.$ - Figure 6$)$.

Table 2. Mean (standard deviation) of $\mu \mathrm{SBS}(\mathrm{MPa})$ for all experimental groups to primary enamel and dentin.

\begin{tabular}{|c|c|c|}
\hline GIC Substrate & Enamel & Dentin \\
\hline Fuji IX & $5.95( \pm 0.85)^{a}$ & $7.01( \pm 1.06)^{\circ}$ \\
\hline Ketac Molar Easy Mix & $5.91( \pm 0.78)^{a}$ & $6.88( \pm 1.35)^{\circ}$ \\
\hline Maxxion R & $3.93( \pm 0.38)^{b}$ & $5.04( \pm 0.70)^{b}$ \\
\hline
\end{tabular}

*Different letters indicate statistically significant differences $(p<0.05)$.

Table 3. Percentage of the failure modes according to GIC and substrate.

\begin{tabular}{lllllll}
\hline & \multicolumn{3}{c}{ Dentin } & \multicolumn{3}{c}{ Enamel } \\
\cline { 2 - 7 } & FIX & KM & MX & FIX & KM & MX \\
\hline Adhesive/mixed & $85 \%$ & $77.5 \%$ & $72.5 \%$ & $81 \%$ & $81 \%$ & $80 \%$ \\
Cohesive in GIC & $5 \%$ & $7.5 \%$ & $2.5 \%$ & $4 \%$ & $4 \%$ & $5 \%$ \\
Premature failures & $10 \%$ & $15 \%$ & $25 \%$ & $15 \%$ & $15 \%$ & $15 \%$ \\
\hline
\end{tabular}

\section{Discussion}

An in vitro study was conducted to verify whether low-priced GIC could be an alternative to ART, without compromising the effectiveness of treatment. GIC presents some favorable properties such as biocompatibility and a coefficient of thermal expansion similar to that of the teeth, ${ }^{6,7,89}$ which are determined by the composition of the material and are closely related to clinical performance. Other properties include water sorption and solubility, which can damage restorations permanently. ${ }^{11}$

Water is important in GIC composition. It is initially responsible for carrying calcium and aluminum ions, which react with polyacrylic acid, thus building the matrix. ${ }^{18}$ Loss of water hinders ionic bonding ${ }^{19}$ and may result in cracks in the restorations. ${ }^{18,20}$ Conversely,

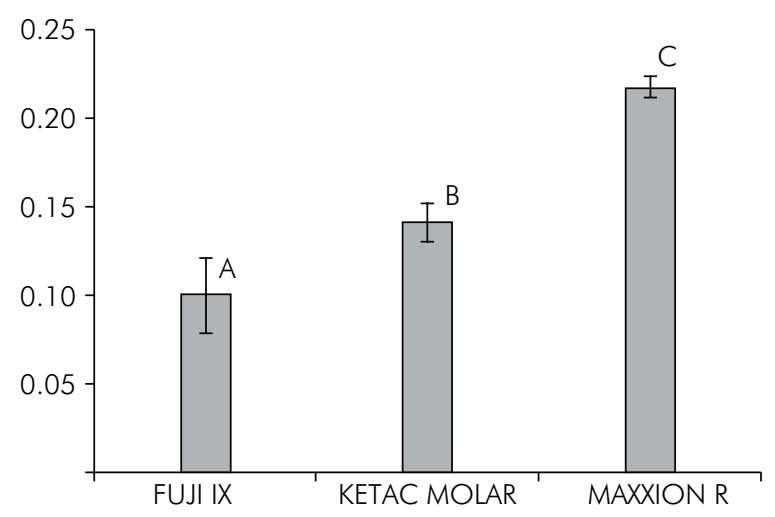

Figure 1. Mean and standard deviation $\left(\mu \mathrm{g} / \mathrm{mm}^{3}\right)$ of water sorption for all materials tested.

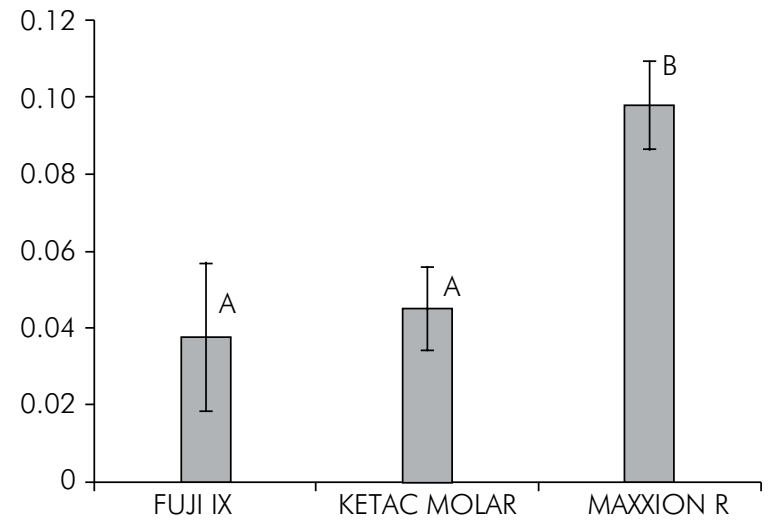

Figure 2. Mean and standard deviation $\left(\mu \mathrm{g} / \mathrm{mm}^{3}\right)$ of solubility for all materials tested. 


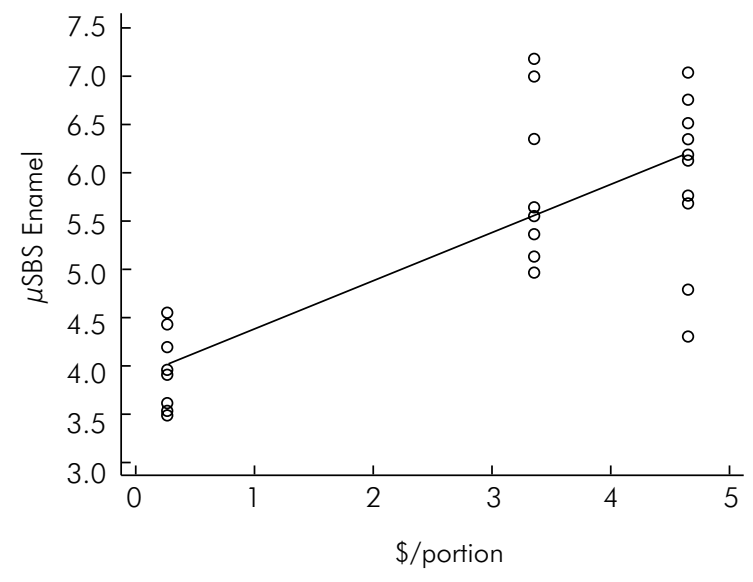

Figure 3. Linear regression: cost versus $\mu$ SBS in enamel.

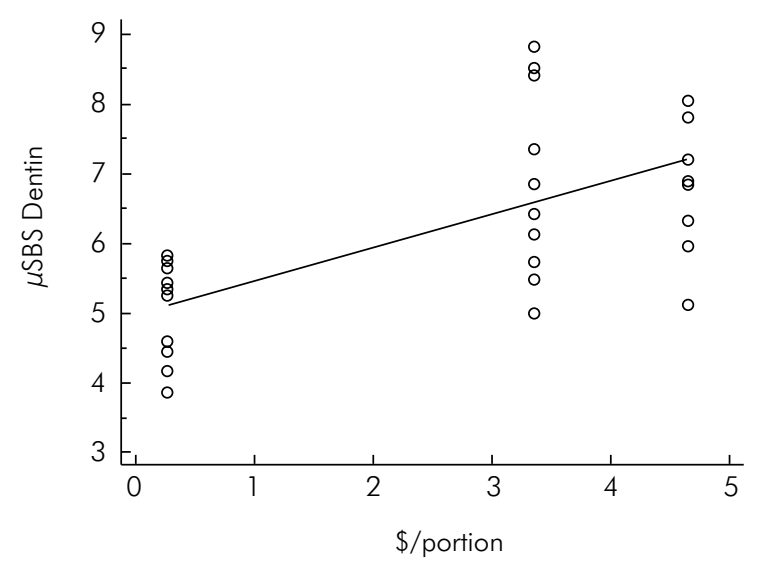

Figure 4. Linear regression: cost versus $\mu$ SBS in dentin.

water adsorption can remove the ions and tamper with the physical properties of the material. ${ }^{21,22}$ The water sorption test showed difference among GIC evaluated, which was inversely proportional to the weight of powder per portion presented in the composition of the materials. The absorption of water molecules results in loss of monomers and other small molecules. ${ }^{23}$

On the other hand, the solubility of MX was higher than that of the other materials, without any difference between FIX and KM. This could be explained by the lower powder to liquid ratio, resulting in fewer ionic bonds available for matrix formation and, consequently, in greater solubilization of the material.

GIC also release fluoride ions, which interfere in the demineralization and remineralization processes

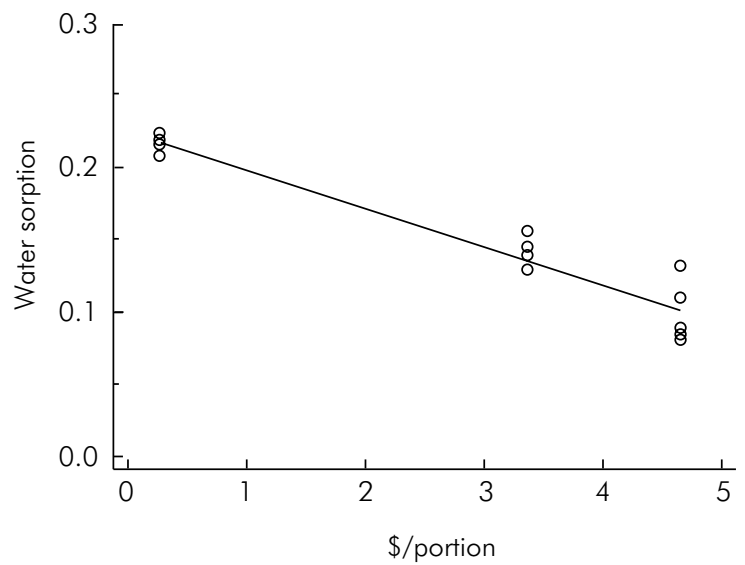

Figure 5. Linear regression: cost versus water sorption.

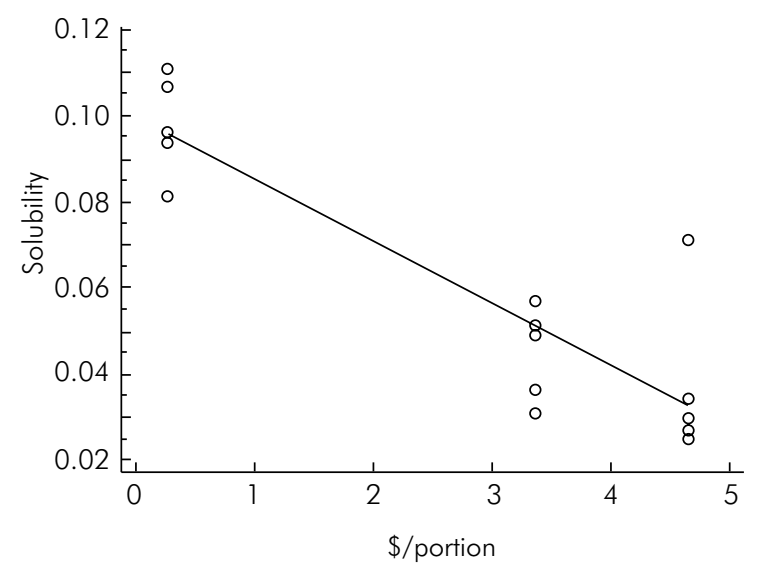

Figure 6. Linear regression: cost versus solubility.

and prevent caries lesions in the area adjacent to the restoration. ${ }^{24}$ As pointed out previously, the release of fluoride by the material is likely to be directly related to its solubility. Thus, future studies are important to determine the influence of solubility on the release of fluoride by GIC.

The main bonding strategy of HVGIC is achieved through ionic bonds between components of the material and hydroxyapatite from the substrate. ${ }^{25} \mathrm{MX}$ showed the lowest bond strength, regardless of the substrate (enamel or dentin), which is in line with the results found by Carvalho et al..$^{26} \mathrm{~A}$ possible explanation for these results would be the composition of MX, as previously demonstrated for the other properties.

Furthermore, the results obtained with GIC are similar to those published previously. ${ }^{27,28} \mathrm{Cruz}$ et al. ${ }^{27}$ evaluated the microshear bond strength in the dentin of 
bovine teeth and reported KM values around 7.0 Mpa, as also observed in this study. The same results were also verified by Tedesco et al. ${ }^{28}$ On the other hand, when the bond strength performance of GIC was evaluated by the microtensile bond strength test, higher values were obtained. ${ }^{29}$ This lack of consensus may be due to the different methodologies used to assess bond strength. However, there is evidence in favor of this methodology for the determination of the bond strength of bristle materials (e.g., GIC). ${ }^{15}$ The failure modes were classified mostly as adhesive/mixed in our study. That is why this type of test was chosen.

The cost of materials was positively associated with $\mu \mathrm{SBS}$, but negatively associated with water sorption and solubility. The performance of low-priced GIC was worse than that of the other GIC. The same applies to the other materials, since the material with the highest powder to liquid ratio also had the best mechanical properties. These results could be related to the powder to liquid ratio of this GIC. A previous study suggested that a powder : liquid ratio higher than 3.6:1 (g:g) would be necessary for a GIC to be labeled as high-viscosity, but that was not reported for MX..$^{30}$ The selection of this material should also take into account the cost associated with all procedures used in the treatment. It may be hypothesized that when materials with poorer properties are used, restorations will have to be replaced more often than it would be necessary if another material were chosen. It implicates in other sources of cost, for

\section{References}

1. Frencken JE, Holmgren CJ, van Palenstein Helderman WH. Basic package of oral care. WHO Collaboration Centre for Oral Health Care Planning and Future Scenarios. The Netherlands: Nijmegen; 2003.

2. Schriks MC, Amerongen WE. Atraumatic perspectives of ART: psychological and physiological aspects of treatment with and without rotary instruments. Community Dent Oral Epidemiol. 2003;31(1):15-20. doi:10.1034/j.1600-0528.2003.00021.x

3. Carvalho TS, Ribeiro TR, Bönecker M, Pinheiro EC, Colares V. The atraumatic restorative treatment approach: an "atraumatic" alternative. Med Oral Patol Oral Cir Bucal. 2009;14(12):e668-73. doi:10.4317/medoral.14.e668

4. Goud RS, Nagesh L, Shoba F, Raju HG. Assessment of discomfort experienced by school children while performing instance, to the length of treatment, dentist's fees, and equipment wear and tear. However, since the cost of this GIC was at least 10 times lower than other ones, the increase in the powder:liquid ratio could improve the performance of this material, even when low-priced materials are used. Further studies should be performed to evaluate whether the replacement of this material in the case of failures would bring significant savings to governmental programs.

\section{Conclusion}

The materials indicated for ART differ in terms of physical and mechanical properties; in addition, low-priced materials may interfere with GIC properties.

\section{Acknowledgments}

We would like to thank Coordenação de Aperfeiçoamento de Pessoal de Nivel Superior - CAPES, Conselho Nacional de Desenvolvimento Científico e Tecnológico - CNPq (141486/2014-7) and Fundação de Amparo à Pesquisa do Estado de São Paulo - FAPESP (2012/11846-5) for their financial support. We are also indebted to the participants of the Pediatric Dentistry Seminar, held by the Graduate Program of the School of Dentistry of Universidade de São Paulo - USP, for their critical comments. Daniela Prócida Raggio and Mariana Minatel Braga are recipients of the Research Productivity Scholarship - CNPq (303109/2012-2 and 308736/2012-5).

'ART' and 'MCP': an experimental study. J Dent (Tehran). 2012;9(4):329-37.

5. Mata C, Allen PF, Cronin M, O'Mahony D, McKenna G, Woods N. Cost-effectiveness of ART restorations in elderly adults: a randomized clinical trial. Community Dent Oral Epidemiol. 2014;42(1):79-87. doi:10.1111/cdoe.12066

6. Amorim RG, Leal SC, Frencken JE. Survival of atraumatic restorative treatment (ART) sealants and restorations: a meta-analysis. Clin Oral Investig. 2012;16(2):429-41. doi:10.1007/s00784-011-0513-3

7. Bonifácio CC, Kleverlaan CJ, Raggio DP, Werner A, Carvalho RC, Amerongen WE. Physical-mechanical properties of glass ionomer cements indicated for atraumatic restorative treatment. Aust Dent J. 2009;54(3):233-7. doi:10.1111/j.1834-7819.2009.01125.x 
8. Paschoal MA, Gurgel CV, Rios D, Magalhães AC, Buzalaf MA, Machado MA. Fluoride release profile of a nanofilled resin-modified glass ionomer cement. Braz Dent J. 2011;22(4):275-9. doi:10.1590/S0103-64402011000400002

9. Hattab FN, Amin WM. Fluoride release from glass ionomer restorative materials and the effects of surface coating. Biomaterials. 2001;22(12):1449-58. doi:10.1016/S0142-9612(00)00253-2

10. Guglielmi CA, Raggio DP, Takeuti ML, Camargo LB, Imparato JC. [Fluoride release and uptake of glass ionomer cements indicated for atraumatic restorative treatment]. Pesq Bras Odontoped Clin Integr. 2011;11(4):561-5. Portuguese. doi:10.4034/PBOCI.2011.114.17

11. Dionysopoulos P, Kotsanos N, Pataridou A. Fluoride release and uptake by four new fluoride releasing restorative materials. J Oral Rehabil. 2003;30(9):866-72. doi:10.1046/j.1365-2842.2003.00993.x

12. McLean JW. Clinical applications of glass-ionomer cements. Oper Dent. 1992;16(Suppl 5):184-90.

13. Pentz MA, Jasuja GK, Rohrbach LA, Sussman S, Bardo MT. Translation in tobacco and drug abuse prevention research. Eval Health Prof. 2006;29(2):246-71. doi:10.1177/0163278706287347

14. Pashley DH, Sano H, Ciucchi B, Yoshiyama M, Carvalho RM. Adhesion testing of dentin bonding agents: a review. Dent Mater. 1995;11(2):117-25. doi:10.1016/0109-5641(95)80046-8.

15. Bonifácio CC, Shimaoka AM, Andrade AP, Raggio DP, Amerongen WE, de Carvalho RC. Micro-mechanical bond strength tests for the assessment of the adhesion of GIC to dentine. Acta Odontol Scand. 2012;70(6):555-63. doi:10.3109/00016357.2011.640280

16. Cefaly DF, Franco EB, Mondelli RF, Francisconi PA, Navarro MF. Diametral tensile strength and water sorption of glass-ionomer cements used in Atraumatic Restorative Treatment. J Appl Oral Sci. 2003;11(2):96-101. doi:10.1590/S1678-77572003000200003

17. Behr M, Rosentritt M, Loher H, Kolbeck C, Trempler C, Stemplinger $\mathrm{B}$ et al. Changes of cement properties caused by mixing errors: the therapeutic range of different cement types. Dent Mater. 2008;24(9):1187-93. doi:10.1016/j.dental.2008.01.013

18. Mortier E, Gerdolle DA, Jacquot B, Panighi MM. Importance of water sorption and solubility studies for couple bonding agent: resin-based filling material. Oper Dent. 2004;29(6):669-76.
19. Young AM, Sherpa A, Pearson G, Schottlander B, Waters DN. Use of Raman spectroscopy in the characterisation of the acid-base reaction in glass-ionomer cements. Biomaterials. 2000;21(19):1971-9. doi:10.1016/S0142-9612(00)00081-8

20. Feilzer AJ, Kakaboura AI, de Gee AJ, Davidson CL. The influence of water sorption on the development of setting shrinkage stress in traditional and resin-modified glass ionomer cements. Dent Mater. 1995;11(3):186-90. doi:10.1016/0109-5641(95)80016-6

21. Causton BE. The physico-mechanical consequences of exposing glass ionomer cements to water during setting. Biomaterials. 1981;2(2):112-5. doi:10.1016/0142-9612(81)90008-9

22. Phillips S, Bishop BM. An in vitro study of the effect of moisture on glass-ionomer cement. Quintessence Int. 1985;16(2):175-7.

23. Chai J, Takahashi Y, Hisama K, Shimizu H. Water sorption and dimensional stability of three glass fiber-reinforced composites. Int J Prosthodont. 2004;17(2):195-9.

24. Mickenautsch S, Yengopal V. Demineralization of hard tooth tissue adjacent to resin-modified glass-ionomers and composite resins: a quantitative systematic review. J Oral Sci. 2010;52(3):347-57. doi:10.2334/josnusd.52.347

25. Lin A, McIntyre NS, Davidson RD. Studies on the adhesion of glass-ionomer cements to dentin. J Dent Res. 1992;71(11):1836-1841. doi:10.1177/00220345920710111401

26. Carvalho TS, van Amerongen WE, de Gee A, Bönecker M, Sampaio FC. Shear bond strengths of three glass ionomer cements to enamel and dentine. Med Oral Patol Oral Cir Bucal. 2011;16(3):e406-10. doi:10.4317/medoral.16.e406

27. Cruz JB, Lenzi TL, Tedesco TK, Guglielmi CA, Raggio DP. Eroded dentin does not jeopardize the bond strength of adhesive restorative materials. Braz Oral Res. 2012;26(4):306-12. doi:10.1590/S1806-83242012005000009

28. Tedesco TK, Bonifácio CC, Hesse D, Kleverlaan CJ, Lenzi TL, Raggio DP. Bonding longevity of flowable GIC layer in artificially carious dentin. Int J Adhes Adhes. 2014;51:62-6. doi:10.1016/j.ijadhadh.2014.02.011

29. Calvo AF, Alves FB, Lenzi TL, Tedesco TK, Reis A, Loguercio AD et al. Glass ionomer cements bond stability in caries-affected primary dentin. Int J Adhes Adhes. 2014;48:183-7. doi:10.1016/j.ijadhadh.2013.09.047

30. Hof MA, Frencken JE, Palenstein Helderman WH, Holmgren CJ. The atraumatic restorative treatment (ART) approach for managing dental caries: a meta-analysis. Int Dent J. 2006;56(6):345-51. doi:10.1111/j.1875-595X.2006.tb00339.x 